\title{
BMJ Open Diverging prevalences and different risk factors for childhood asthma and eczema: a cross-sectional study
}

\author{
Maxwell S Barnish, ${ }^{1,2}$ Nara Tagiyeva, ${ }^{2}$ Graham Devereux, ${ }^{2}$ Lorna Aucott, ${ }^{3}$ \\ Steve Turner ${ }^{2}$
}

To cite: Barnish MS,

Tagiyeva N, Devereux G, et al. Diverging prevalences and different risk factors for childhood asthma and eczema: a crosssectional study. BMJ Open 2015;5:e008446. doi:10.1136/bmjopen-2015008446

- Prepublication history and additional material is available. To view please visit the journal (http://dx.doi.org/ 10.1136/bmjopen-2015008446)

Received 9 April 2015 Accepted 15 May 2015

CrossMark

\author{
${ }^{1}$ Epidemiology Group, \\ University of Aberdeen, \\ Aberdeen, UK \\ ${ }^{2}$ Child Health, University of \\ Aberdeen, Aberdeen, UK \\ ${ }^{3}$ Medical Statistics Team, \\ University of Aberdeen, \\ Aberdeen, UK
}

Correspondence to Dr Maxwell S Barnish; maxwell.barnish@abdn.ac.uk

\section{ABSTRACT}

Objective: To compare the prevalences of and risk factors for asthma, wheeze, hay fever and eczema in primary schoolchildren in Aberdeen in 2014.

Design: Cross-sectional survey.

Setting: Primary schools in Aberdeen, North-East Scotland.

Participants: Children in Scottish school years primary 1-7 were handed a questionnaire by their class teacher to be completed by their parents and returned to the researchers by post or online.

Main outcome measures: Lifetime history of asthma, eczema and hay fever, and recent history of wheeze.

Results: 41 schools agreed to participate $(87 \%)$. 11249 questionnaires were distributed and 3935 returned $(35 \%)$. A parent-reported lifetime history of asthma, eczema and hay fever was present in $14 \%$, $30 \%$ and $24 \%$ of children, respectively. The odds of lifetime asthma increased with age (OR 1.1 per year, $95 \% \mathrm{Cl} 1.1$ to 1.2 ), male sex (OR $1.89,95 \% \mathrm{Cl} 1.4$ to 2.3), parental smoking ( $\mathrm{OR} 1.7,95 \% \mathrm{Cl} 1.2$ to 2.3 ) and eczema (OR 6.6, 95\% Cl 5.2 to 8.4). Prevalence of recent wheeze was also reported to be $14 \%$ and was positively associated with male sex, parental smoking and eczema. In contrast, parental eczema was the only identified predictor of childhood eczema risk.

Conclusions: The lifetime prevalence of asthma in primary schoolchildren was $14 \%$ in this survey, approximately half the prevalence of eczema. We report diverging prevalences in relation to previous studies in our locality, and different risk factors for asthma and eczema. These findings suggest that asthma and eczema are unlikely to have a common origin.

\section{INTRODUCTION}

Asthma is the most common chronic childhood medical condition worldwide ${ }^{1}$ and places a significant burden on family life, society and healthcare systems. ${ }^{2}{ }^{3}$ The prevalence of childhood asthma in Aberdeen, the UK as a whole, and the wider western world rose sharply during the second half of the 20 th century. Since the turn of the century,

\section{Strengths and limitations of this study}

- The Aberdeen Schools Asthma Survey (ASAS) is one of the longest-running paediatric epidemiology studies in the world.

- It uses common methodology over successive cross-sectional surveys of a defined population.

- ASAS 2014 includes the entire primary school age and expands the geographical area to the modern Aberdeen city boundaries, while maintaining a subgroup using the old criteria for comparison with previous ASAS.

- The use of imputation also enabled up to an additional 349 children to be included in prevalence figures, increasing robustness.

- A limitation is the $35 \%$ response rate which may limit the representativeness of the findings.

the global pattern has been far less certain. A UK wide review has provided evidence of a possible fall in childhood asthma prevalence. ${ }^{4}$ In Merseyside, ${ }^{5}$ a fall in childhood asthma prevalence was witnessed between 1998 and 2006. Although a falling prevalence of childhood asthma has also been detected in Canada $^{6}$ and Australia, ${ }^{7}$ it has been suggested that, globally, rises remain more common than falls. ${ }^{8}$ The International Study of Asthma and Allergy in Children (ISAAC) undertook three surveys of asthma prevalence in many countries between 1991 and 2003, and found evidence of asthma prevalence in 13-14 year olds still rising in some countries (eg, Central America, Spain, Portugal and Eastern Europe), of having reached a plateau in some countries (eg, New Zealand, Brazil and Uruguay) and declining in some others (eg, the UK). ${ }^{9}$ As a result of this widespread geographical variation in paediatric asthma prevalence, repeated surveys in the same locations, which give an insight into the burden of asthma allow for the planning and delivery of healthcare. 
The Aberdeen Schools Asthma Survey (ASAS) was first carried out in 1964 and is the longest-running series of surveys of its kind in the UK and among the longest-running worldwide. In Aberdeen schoolchildren aged 9-12, the lifetime prevalence of asthma rose from $4 \%$ in 1964 to $28 \%$ in 2004 , but fell to $22 \%$ in 2009 . In contrast with the fall in asthma (and wheeze) between 2004 and 2009, the prevalence of eczema and hay fever remained relatively unchanged. ${ }^{10-12}$

The divergence in asthma and eczema prevalences seen in Aberdeen 2004-2009, and elsewhere, ${ }^{13}$ lead us to speculate that there may be different causal pathways for asthma and eczema. Here we test the hypotheses that (1) prevalences of asthma and eczema will continue to diverge beyond 2009 in Aberdeen children and that (2) different risk factors will be associated with asthma and eczema. To test these hypotheses, and specifically to increase the age range and socioeconomic diversity of the study population, we modified the inclusion criteria used in previous ASAS from children aged 9-12 attending schools within the 1964 Aberdeen City boundaries to all primary school children (ie, aged 5-12) attending schools within the 2014 Aberdeen City limits.

\section{METHODS}

\section{Study design and setting}

A cross-sectional survey design was used. All state-run primary schools under the jurisdiction of Aberdeen City Council in North-East Scotland were invited to participate.

\section{Participants}

All children in primary classes in participating schools were eligible for the study. Class teachers in participating schools distributed questionnaires to all children in the primary classes of the school (Scottish school years primary 1-7, approximate ages 5-12 years) in May 2014. All previous ASAS were also carried out in May and this consistency excludes the potential for seasonal variation in asthma symptoms to influence parental recall and reporting of symptoms. The study size was determined by the number of children attending schools in Aberdeen city, school participation rate and parental response rate. Since this was a population epidemiology study, it was not appropriate to predetermine a sample size. Children gave the questionnaire to their parents, who completed it at home and posted it directly to the researchers. An electronic web-based response option was offered as an alternative to the paper questionnaire. Although it was not possible to contact nonresponders directly due to the Data Protection Act (1998; DPA), press releases were made and posters put up at schools with historically low response rates in an attempt to encourage parents to complete the questionnaire and thus, reduce response bias. The denominator in calculating response rates was taken to be the school roll figures provided by the school office to the researchers shortly prior to the delivery of questionnaires to the school.

\section{Measures}

The questionnaire validated in previous ASAS years was distributed with a letter explaining its purpose. The key questions included those asked since the 1964 survey: 'Has your child wheezed or had a whistle in the chest in the past three years?', 'Has your child ever had asthma?', 'Has your child ever had eczema?' and 'Has your child ever had hay fever?' Questions used in the wheeze module of the ISAAC study ${ }^{9}$ have been included in 2004 and 2009 surveys and were also included in 2014, including: 'Has your child wheezed in the past 12 months?'. Questions from the Changes in Childhood Exposure to Environmental Tobacco Smoke (CHETS) study $^{14}$ were also included this year to explore in more detail children's risk of secondhand smoke exposure. Full details of the questionnaire are presented in the online supplement. A $10 \%$ random re-entry check, conducted on the data for quality control purposes, was completed successfully. Socioeconomic classification at the postcode level was obtained for each participating child using the 2012 Scottish Index of Multiple Deprivation (SIMD),${ }^{15}$ which is the official index of socioeconomic status used by the Scottish Government and covers seven domains: income, employment, health, education, geographic access, housing and crime. The SIMD quintile measure was used to code socioeconomic status from 1 (least deprived) to 5 (most deprived).

\section{Data analysis}

\section{Imputation of missing values}

As previously, ${ }^{12}$ imputation of asthma, eczema and hay fever was conducted for responses where only the wheeze question was answered.

\section{Descriptive prevalence statistics}

Mean prevalence with SD and 95\% CIs were calculated for the lifetime prevalence of asthma, eczema, hay fever, wheeze in the past 12 months and wheeze in the past 3 years. These figures were for all children and separately for boys and girls. A subgroup of children aged 9-12 at school within the 1964 Aberdeen city boundaries was created to allow for direct comparisons with previous ASAS studies.

\section{Predictors of childhood wheeze, asthma, eczema and hay fever}

Five logistic regression models were constructed with observed prevalence of wheeze in the past 12 months and past 3 years, and lifetime asthma, eczema and hay fever as dependent variables. Age, sex, SIMD and number of parental smokers were included as independent variables. Parental prevalence for the corresponding child outcome measure was included in models of asthma, eczema and hay fever. Eczema was also included as an index of atopy in the models where asthma, wheeze and hay fever were the outcome. Standard statistical software was used (SPSS V.22.0.0.1 IBM, Armonk, New York, USA) and a $p$ value of $<0.05$ was assumed to be significant. 


\section{RESULTS}

\section{Study participants}

Forty-one $(87 \%)$ of 47 schools invited to take part agreed to participate. According to projected school roll figures for $2014,{ }^{16}$ this denied access to 1585 children. There was, however, no discernible socioeconomic pattern with regard to school participation. There were 11249 children in participating schools with 3935 questionnaires returned $(35 \%)$. School-level response rates ranged from $17 \%$ to $60 \%$. Higher SIMD was associated with significantly higher response rates $\left(r_{41}=0.609\right.$, $\mathrm{p}<0.001)$. Figure 1 shows the detailed recruitment pathway for ASAS 2014.

\section{Prevalences of asthma, eczema, hay fever and wheeze}

The prevalence estimates for asthma, eczema and hay fever, 12 month wheeze and 3 year wheeze were $14 \%$, $30 \%, 24 \%, 14 \%$ and $18 \%$, respectively, for the entire data set (table 1). Excluding completely blank questionnaires, the missing data rates were $1 \%$ for age, gender and 12 month wheeze, $3 \%$ for SIMD and 3 year wheeze, $9 \%$ for lifetime eczema prevalence and $10 \%$ for lifetime asthma and hay fever prevalence. Among the subgroup for comparison with previous ASAS surveys (ie, those aged 9-12 and within the 1964 city boundaries), the prevalence of asthma, eczema, hay fever, 12 month and 3 year wheeze were $19 \%, 29 \%, 30 \%, 14 \%$ and $18 \%$ (table 2), respectively. Time trends for asthma, eczema, hay fever and wheeze are shown in figure 2. Raw comparable data for 2014 are provided in table 2 and those for previous years can be found in our previous reports. ${ }^{10-12}$

\section{Factors associated with asthma and other outcomes}

Wheeze in the past 12 months and 3 years were significantly associated with male sex, parental smoking and

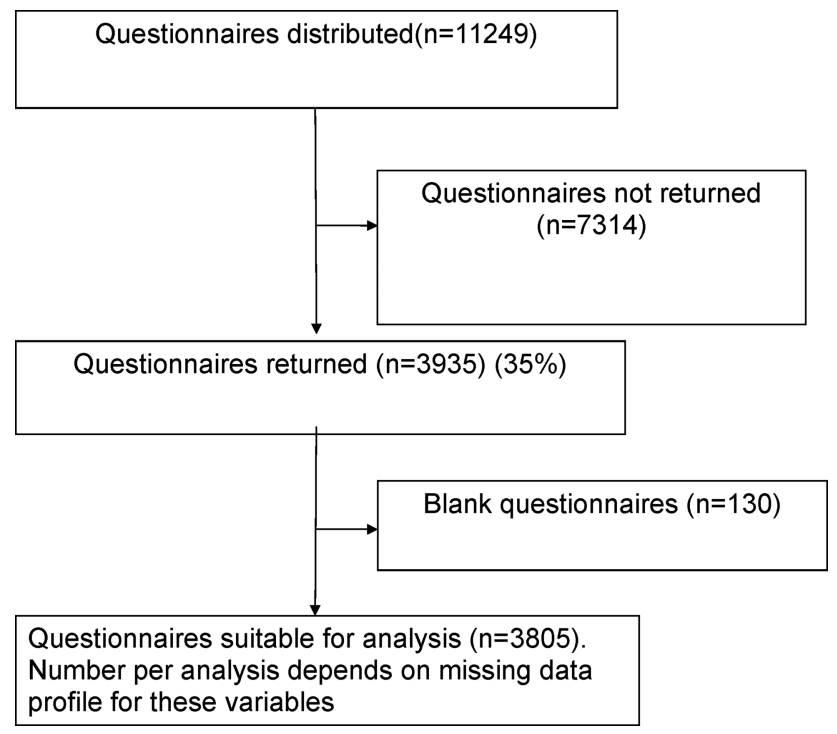

Figure 1 Consort-style figure summarising the number of participants in the 2014 Aberdeen Schools Asthma Survey. childhood eczema, but not with age or SIMD. Lifetime prevalence of asthma was positively associated with age, male sex, parental smoking, childhood eczema and parental asthma, but not with SIMD. Lifetime prevalence of eczema was significantly associated with parental eczema, but not with age, sex, SIMD or parental smoking. Lifetime prevalence of hay fever was associated with increased age, male sex, childhood eczema and parental hay fever, but not with SIMD or parental smoking (table 3).

\section{DISCUSSION}

Childhood asthma and atopy (as evidenced here by eczema) are common chronic conditions which lead to morbidity and poor quality of life for both child and parent and therefore, merit close surveillance to allow planning of healthcare delivery. ASAS 2014 provides an up-to-date assessment of asthma and eczema prevalence, and previous survey results have been consistent with prevalences in the UK. The first main finding of this study is that asthma and eczema both remain common in today's childhood population. Asthma, but not eczema, prevalence has fallen since our 1999 and 2004 surveys, but is still approximately twice the prevalence reported in 1989. The second main finding is the divergent trends in asthma and eczema prevalence which, coupled with the associations between age, parental smoking and sex with asthma but not with eczema, suggest that there may be different underlying causal pathways for asthma and atopy or non-respiratory allergic conditions. The fall in asthma prevalence and its association with parental smoking is pertinent in the context of the Smoking, Health and Social Care (Scotland) Act (2005) which prohibited smoking in enclosed public spaces from March 2006. There is evidence that this Act has reduced childhood hospital admissions for asthma. ${ }^{17}$ Ours is the first survey of childhood asthma prevalence in a Western European population since our previous publication in $2011^{12}$ and gives a novel insight into the burden of childhood asthma; we are confident that the prevalence of childhood asthma is falling and the trend since 2004 suggests that a further fall might be anticipated. Falling asthma prevalence since the year 2000 has previously been noted in Aberdeen $^{12}$ and Merseyside ${ }^{5}$ in the UK, as well as in Ontario, Canada ${ }^{7}$ and Belmont, New South Wales, Australia. ${ }^{8}$ Therefore, the prevalence results reported here are in keeping with observed trends in the UK and certain other Western countries and provide evidence for a continuation of these trends in these localities to 2014. However, the generalisability of asthma epidemiological studies is limited to some extent by widespread geographical variation in prevalence values and trends as revealed by ISAAC. ${ }^{9}$

The relationship between asthma and atopic conditions, such as eczema and hay fever, is complex and our study highlights some of these inconsistencies. For 


\begin{tabular}{|c|c|c|c|c|c|c|}
\hline & \multicolumn{2}{|l|}{ Boys } & \multicolumn{2}{|l|}{ Girls } & \multicolumn{2}{|l|}{ Total } \\
\hline & Raw & Imputed & Raw & Imputed & Raw & Imputed \\
\hline $\mathrm{N}(\%)_{a}$ & $1896(48 \%)$ & & $1903(48 \%)$ & & $3935(100 \%)$ & \\
\hline $\mathrm{Age}_{\mathrm{b}}$ & 9.1 (9.0 to 9.2$)$ & & $8.9(8.8$ to 9.0$)$ & & 9.0 (9.0 to 9.1$)$ & \\
\hline $\operatorname{SIMD}_{\mathrm{C}}$ & $5(2)$ & & $4(2)$ & & $4(2)$ & \\
\hline \multicolumn{7}{|l|}{ Parental smokers } \\
\hline Neither & $1531(81 \%)$ & & $1518(80 \%)$ & & $3183(81 \%)$ & \\
\hline One & $239(13 \%)$ & & $260(14 \%)$ & & $501(13 \%)$ & \\
\hline Both & $126(7 \%)$ & & $125(7 \%)$ & & $251(6 \%)$ & \\
\hline \multicolumn{7}{|l|}{ Parental asthma } \\
\hline Neither & $1180(69 \%)$ & & 1189 (69\%) & & 2374 (69\%) & \\
\hline One & $473(28 \%)$ & & $465(27 \%)$ & & $939(27 \%)$ & \\
\hline Both & $60(4 \%)$ & & $65(4 \%)$ & & $125(4 \%)$ & \\
\hline \multicolumn{7}{|l|}{ Parental eczema } \\
\hline Neither & $1178(72 \%)$ & & $1200(73 \%)$ & & $2383(73 \%)$ & \\
\hline One & $405(25 \%)$ & & $405(25 \%)$ & & $811(25 \%)$ & \\
\hline Both & $47(3 \%)$ & & $41(3 \%)$ & & $88(3 \%)$ & \\
\hline \multicolumn{7}{|l|}{ Parental hay fever } \\
\hline Neither & $804(47 \%)$ & & $818(48 \%)$ & & $1626(47 \%)$ & \\
\hline One & $699(41 \%)$ & & 666 (39\%) & & $1367(40 \%)$ & \\
\hline Both & $219(13 \%)$ & & $225(13 \%)$ & & $444(13 \%)$ & \\
\hline Child asthma $a_{d}\left(N_{e}=3426\right)$ & $17.3(15.5$ to 19.1$)$ & $17.0(15.2$ to 18.8$)$ & 11.1 (9.6 to 12.6$)$ & $11.2(9.7$ to 12.7$)$ & $14.2_{\mathrm{f}}(13.0$ to 15.4$)$ & 14.1 (12.9 to 15.2$)$ \\
\hline Child eczema ${ }_{d}\left(N_{e}=3462\right)$ & 31.2 (29.0 to 33.4 ) & 31.4 (29.2 to 33.6$)$ & 29.1 (27.0 to 31.2$)$ & 29.0 (26.9 to 31.2 ) & 30.2 (28.6 to 31.7$)$ & 30.2 (28.7 to 31.7 ) \\
\hline Child hay fever $\left(\mathrm{N}_{\mathrm{e}}=3425\right)$ & 26.6 (24.5 to 28.7$)$ & 26.78 (24.6 to 28.8$)$ & 21.6 (19.6 to 23.5$)$ & 21.9 (19.9 to 23.8 ) & $24.1 \mathrm{~g}$ (22.7 to 25.5$)$ & 24.3 (22.8 to 25.7$)$ \\
\hline Child wheeze 3 years $(\mathrm{N}=3800)$ & 21.5 (19.7 to 23.4 ) & & 15.4 (13.8 to 17.0$)$ & & $18.4_{\mathrm{f}}(17.29$ to 19.7$)$ & \\
\hline Child wheeze 12 months $_{d}(\mathrm{~N}=3772)$ & $16.2(14.6$ to 17.9$)$ & & $11.8(10.4$ to 13.3$)$ & & $14.0_{\mathrm{f}}(12.9$ to 15.1$)$ & \\
\hline
\end{tabular}

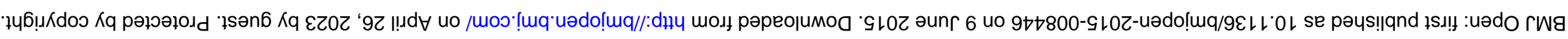


Table 2 Demographics and prevalence of wheeze, asthma, eczema and hay fever among primary schoolchildren aged 9-12 in the 1964 city of Aberdeen in 2014.

\begin{tabular}{|c|c|c|c|c|c|c|}
\hline & \multicolumn{2}{|l|}{ Boys } & \multicolumn{2}{|l|}{ Girls } & \multicolumn{2}{|l|}{ Total } \\
\hline & Raw & Imputed & Raw & Imputed & Raw & Imputed \\
\hline $\mathrm{N}(\%)$ & $402(50 \%)$ & & $406(50 \%)$ & & $808(100 \%)$ & \\
\hline $\mathrm{Age}_{\mathrm{a}}$ & 11.29 (11.18 to 11.3$)$ & & 11.11 (11.0 to 11.2 ) & & $11.2(11.1$ to 11.2$)$ & \\
\hline $\operatorname{SIMD}_{\mathrm{b}}$ & $3(3)$ & & $3(3)$ & & $3(3)$ & \\
\hline \multicolumn{7}{|l|}{ Parental smokers } \\
\hline Neither & $306(76 \%)$ & & $298(73 \%)$ & & $606(75 \%)$ & \\
\hline One & $58(14 \%)$ & & $77(19 \%)$ & & $135(17 \%)$ & \\
\hline Both & $38(10 \%)$ & & $31(8 \%)$ & & $69(9 \%)$ & \\
\hline \multicolumn{7}{|l|}{ Parental asthma } \\
\hline Neither & $248(70 \%)$ & & $253(70 \%)$ & & $501(70 \%)$ & \\
\hline One & $98(28 \%)$ & & $88(24 \%)$ & & $186(26 \%)$ & \\
\hline Both & $9(3 \%)$ & & $19(5 \%)$ & & $28(4 \%)$ & \\
\hline \multicolumn{7}{|l|}{ Parental eczema } \\
\hline Neither & $233(71 \%)$ & & $258(75 \%)$ & & 491 (73\%) & \\
\hline One & $89(27 \%)$ & & $75(22 \%)$ & & $164(24 \%)$ & \\
\hline Both & $7(2 \%)$ & & $12(4 \%)$ & & $19(3 \%)$ & \\
\hline \multicolumn{7}{|l|}{ Parental hay fever } \\
\hline Neither & $178(51 \%)$ & & $175(48 \%)$ & & $353(49 \%)$ & \\
\hline One & $130(37 \%)$ & & $147(41 \%)$ & & 277 (39\%) & \\
\hline Both & $44(13 \%)$ & & $41(11 \%)$ & & $85(12 \%)$ & \\
\hline Child asthma $\mathrm{c}_{\mathrm{c}}\left(\mathrm{N}_{\mathrm{d}}=720\right)$ & 23.6 (19.2 to 27.9$)$ & 23.2 (18.9 to 27.6 ) & 13.7 (10.1 to 17.2$)$ & 14.0 (10.4 to 17.6$)$ & $18.6_{\mathrm{e}}(15.8$ to 21.5$)$ & 18.6 (15.8 to 21.5$)$ \\
\hline Child eczema $\left(\mathrm{N}_{\mathrm{d}}=708\right)$ & 28.6 (23.8 to 33.3 ) & 29.0 (24.3 to 33.8 ) & 29.15 (24.3 to 33.8 ) & 29.2 (24.5 to 33.9$)$ & 28.8 (25.5 to 32.2$)$ & 29.1 (25.9 to 32.5$)$ \\
\hline Child hay fever ${ }_{c}\left(N_{d}=724\right)$ & 29.9 (25.3 to 34.7$)$ & $30.3(25.6$ to 35.1$)$ & 29.8 (25.0 to 34.4$)$ & 30.1 (25.4 to 34.8 ) & $29.8_{\mathrm{e}}(26.5$ to 33.2$)$ & 30.2 (26.9 to 33.6$)$ \\
\hline Wheeze 3 yrs $(\mathrm{N}=805)$ & $23.9(19.8$ to 28.1$)$ & & $12.6(9.4$ to 15.9$)$ & & $18.3_{\mathrm{e}}(15.6$ to 20.9$)$ & \\
\hline Wheeze $12 \mathrm{mths}_{\mathrm{c}}(\mathrm{N}=800)$ & $17.8(14.0$ to 21.5$)$ & & $10.0(7.1$ to 12.9$)$ & & $13.9_{\mathrm{e}}(11.58$ to 16.3$)$ & \\
\hline
\end{tabular}


Asthma prevalence $(95 \%$ Cls $)$

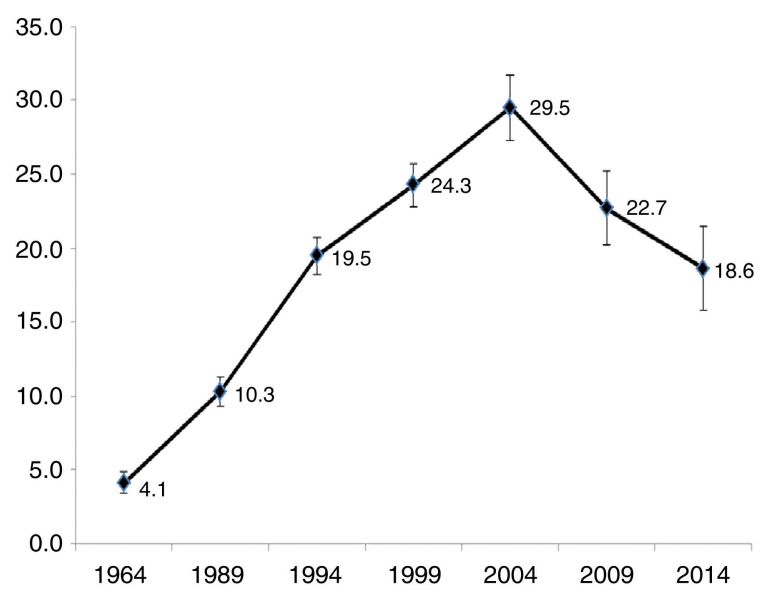

Hay fever prevalence (p5\% Cls)

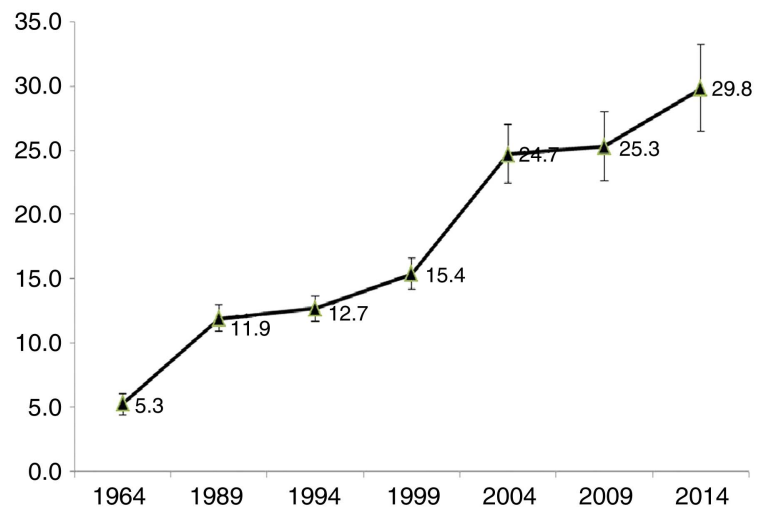

Eczema prevalence $(95 \% \mathrm{Cls})$

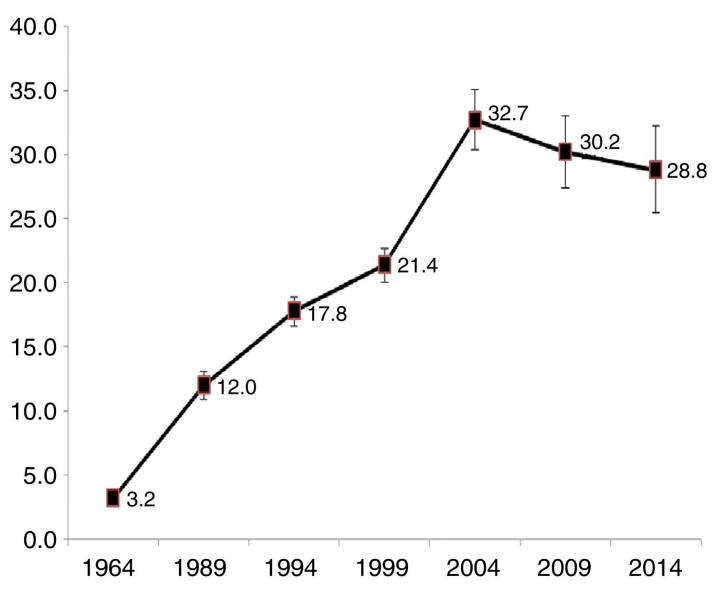

3 year wheeze prevalence $(95 \% \mathrm{Cls})$

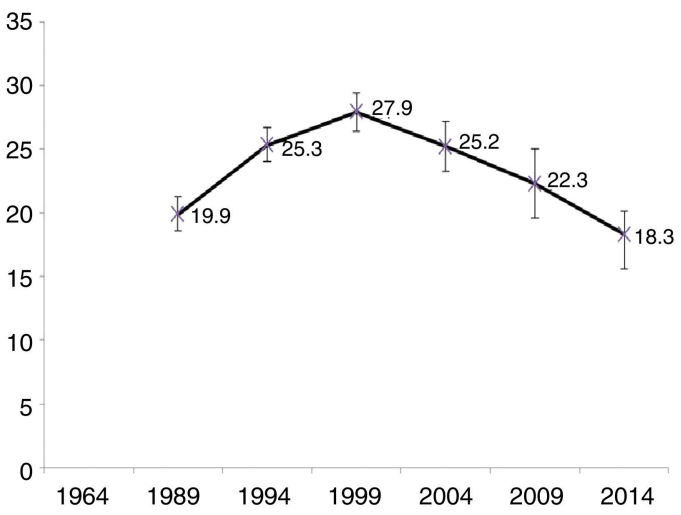

Figure 2 Time trends for prevalence of wheeze, asthma, eczema and hay fever among primary schoolchildren aged 9-12 in the 1964 city of Aberdeen 1964-2014. Dots on the line represent mean prevalence and bars represent $95 \%$ Cls.

example, the parallel rise in asthma and eczema prevalence seen in ASAS between 1964 and 2004, and the sixfold increased risk for a child with asthma also having eczema suggest that there might be a common origin for both conditions. Conversely, the divergent trends in prevalence since 2004 and the associations with gender, age and parental smoking for asthma but not eczema are inconsistent with a common origin hypothesis. Hay fever can be considered an allergic condition of the upper airways and our observations show common risk factors for hay fever and asthma, but the same prevalence for eczema. This might be explained by hay fever being a hybrid condition that shares an underlying asthmatic airway abnormality in the upper respiratory tract along with systemic atopy. Atopy is an immunological condition, and eczema ${ }^{18}$ and skin prick reactivity ${ }^{19}$ in infancy are associated with increased risk for later asthma, but there is increasing recognition that the airway epithelial cell, and not the humoral immune system, is important to the development of asthma. ${ }^{20}$ Other reasons for falling prevalence in asthma but not eczema prevalence include changes in diagnostic practice for asthma, but not eczema, and reduced exposure to secondhand smoke (shown here to be related to asthma but not eczema prevalence).

A major strength of ASAS is the common methodology used over successive instances of the longest-running series of paediatric asthma epidemiology studies in the UK and one of the longest-running surveys worldwide. A further strength of ASAS 2014 is the inclusion of a wider age range and updating of the geographical area to the modern city boundaries, which include many suburban developments built following the expansion of the oil industry in Aberdeen in the 1970s and 1980s. This increases its generalisability to the modern population; however, a subgroup was retained using the previous criteria for comparability with earlier studies. Moreover, the sample characteristics of the comparable subgroup in ASAS 2014 are closely matched to those of previous ASAS, suggesting that reduced response rate is unlikely to have fundamentally changed our sample characteristics. The use of imputation also enabled up to an additional 349 children to be included in prevalence figures increasing the robustness. A 


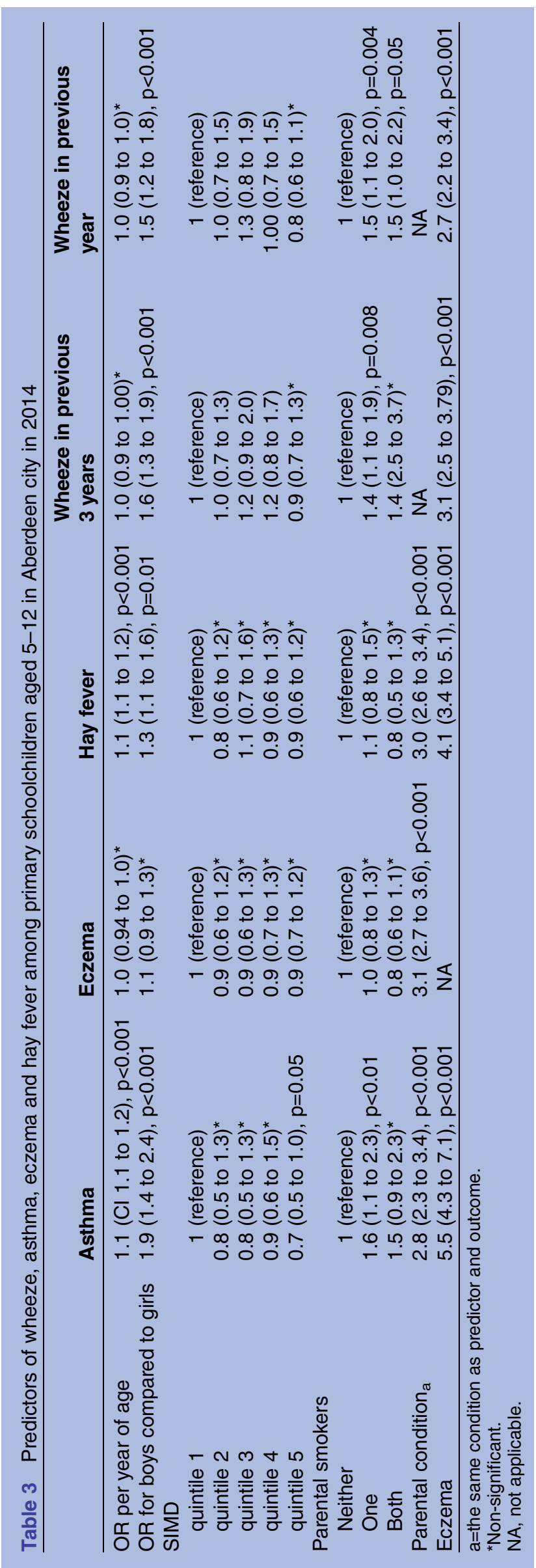

limitation is the $35 \%$ response rate which may limit the representativeness of the findings. Although there was a significant association between SIMD and school-level response rate, SIMD was not associated with the study outcome measures. It is possible that parents of children with asthma were more likely to participate, but this sampling bias would have reduced not exaggerated our observed fall in asthma prevalence and would not threaten the validity of our finding of divergent prevalences for asthma and eczema. Although this approach is widely used and validated in epidemiology, this ASAS, as per all previous ASAS since 1989, relied on parents' report and it is possible that this could have introduced diagnostic bias.

In light of the falling response rates in surveys, such as ours in the $\mathrm{UK}^{21}$ and elsewhere, ${ }^{22}$ it is important to consider whether traditional epidemiological methods are the best approaches to take in future. Although lower than ASAS $2004(57 \%)^{10}$ and $2009(54 \%),{ }^{12}$ our response rate is higher than the 2006 childhood asthma epidemiology study in Merseyside $(30 \%)^{5}$ and an epidemiological study in a different disease area run by a separate team in Aberdeen $(33 \%) .{ }^{23}$ Falling response rates are likely to result from a combination of several factors, including DPA which was instituted in $2000,{ }^{16}$ survey fatigue ${ }^{17}$ and an increase in unsolicited mailing, ${ }^{17}$ that we and other researchers are unable to address. The response rate in ASAS fell from $85 \%$ in ASAS 1999 prior to the enactment of DPA to $57 \%$ in ASAS 2004-the first ASAS in the DPA era. Therefore, it might be better for future UK childhood asthma epidemiological studies to consider using alternative approaches such as anonymised general practitioner prescribing or hospital admissions data to provide a whole population perspective, although these approaches preclude asking targeted questions and rely on information already held on clinical databases. In addition, these approaches do not rely on self-reported or parent-reported measures.

In summary, we report diverging prevalence figures and different predictors for asthma and eczema in primary schoolchildren in Aberdeen, Scotland. These findings are not consistent with the hypothesis that paediatric asthma and eczema have a common origin, suggesting that the conditions are likely to have different underlying mechanisms of action.

Contributors NT, GD, LA and ST were involved in conception and design. $\mathrm{MB}$, NT and ST were involved in project management. MB collected data. MB, LA and ST undertook analysis. MB drafted the initial version of the manuscript and all authors contributed to revisions. ST is the guarantor.

Funding This study was funded by Chest Heart and Stroke Scotland and a private donation from the family of Blanche Dawson, who conducted the initial 1964 Aberdeen Schools Asthma Survey.

Competing interests None declared.

Ethics approval Ethical approval for this study was granted by the University of Aberdeen College of Life Sciences and Medicine Ethics Review Board. 
Governance approval for the recruitment of schools was granted by Aberdeen City Council Learning and Leisure Services.

Provenance and peer review Not commissioned; externally peer reviewed.

Data sharing statement No additional data are available.

Open Access This is an Open Access article distributed in accordance with the Creative Commons Attribution Non Commercial (CC BY-NC 4.0) license, which permits others to distribute, remix, adapt, build upon this work noncommercially, and license their derivative works on different terms, provided the original work is properly cited and the use is non-commercial. See: http:// creativecommons.org/licenses/by-nc/4.0/

\section{REFERENCES}

1. World Health Organization. http://www.who.int/respiratory/asthma/en/ (accessed 6 Apr 2015).

2. Sennhauser FH, Braun-Fahrländer $\mathrm{C}$, Wildhaber $\mathrm{JH}$. The burden of asthma in children: a European perspective. Paediatr Respir Rev 2005;6:2-7.

3. Von Mutius E. The burden of childhood asthma. Arch Dis Child 2000;82(Suppl 2):ii2-5.

4. Anderson HR, Gupta R, Strachan DP, et al. 50 years of asthma: UK trends from 1955 to 2004. Thorax 2007;62:85-90.

5. Koshy G, Delpisheh A, Brabin BJ. Trends in prevalence of childhood and parental asthma in Merseyside, 1991-2006. J Public Health (Oxf) 2010;32:488-95.

6. Gershon AS, Guan J, Wang C, et al. Trends in asthma prevalence and incidence in Ontario, Canada, 1996-2005: a population study. Am J Epidemiol 2010;172:728-36.

7. Toelle BG, $\mathrm{Ng} \mathrm{K}$, Belousova $\mathrm{E}$, et al. Prevalence of asthma and allergy in schoolchildren in Belmont, Australia: three cross sectional surveys over 20 years. BMJ 2004;328:387-7.

8. Anandan $\mathrm{C}$, Nurmatov $\mathrm{U}$, van Schayk OCP, et al. Is the prevalence of asthma declining? Systematic review of epidemiological studies. Allergy 2010;65:152-67.

9. Asher MI, Montefort S, Bjorksten B, et al. Worldwide time trends in the prevalence of symptoms of asthma, allergic rhinoconjunctivitis, and eczema in childhood: ISAAC Phases One and Three repeat multicountry cross-sectional surveys. Lancet 2006;368:733-43.
10. McNeill G, Tagiyeva N, Aucott L, et al. Changes in the prevalence of asthma, eczema and hay fever in pre-pubertal children. Paediatr Perinat Epidemiol 2009;23:506-12.

11. Ninan TK, Russell G. Respiratory symptoms and atopy in Aberdeen schoolchildren: evidence from two surveys 25 years apart. BMJ 1992;304:873-5.

12. Malik G, Tagiyeva N, Aucott $\mathrm{L}$, et al. Changing trends in asthma in 9-12-year-olds between 1964 and 2009. Arch Dis Child 2011;96:227-31.

13. Ponsonby AL, Glasgow N, Pezic A, et al. A temporal decline in asthma but not eczema prevalence from 2000 to 2005 at school entry in the Australian Capital Territory with further consideration of country of birth. Int J Epidemiol 2008;37:559-69.

14. Akhtar PC, Currie DB, Currie CE, et al. Changes in child exposure to environmental tobacco smoke (CHETS) study after implementation of smoke-free legislation in Scotland: national cross-sectional survey. BMJ 2007;335:545-9.

15. Scottish Government. Scottish Index of Multiple Deprivation. http:// www.sns.gov.uk/Simd/Simd.aspx (accessed 6 Apr 2015).

16. Aberdeen City Council [Internet] 2012-based school roll forecasts, Aberdeen City. http://www.aberdeencity.gov.uk/nmsruntime/ saveasdialog.asp? IID=49086\&sID=332 (accessed 6 Apr 2015)

17. Mackay D, Haw S, Ayres JG, et al. Smoke-free legislation and hospitalizations for childhood asthma. N Engl J Med 2010;363:1139-45.

18. Von Kobyletzki LB, Bornehag C-G, Hasselgren M, et al. Eczema in early childhood is strongly associated with the development of asthma and rhinitis in a prospective cohort. BMC Dermatol 2012;12:11.

19. Mullane D, Turner SW, Cox DW, et al. Reduced infant lung function, active smoking, and wheeze in 18-year-old individuals. JAMA Pediatr 2013;167:368-73.

20. Holgate ST, Davies DE, Lackie PM, et al. Epithelial-mesenchymal interactions in the pathogenesis of asthma. J Allergy Clin Immunol 2000;2:193-204.

21. Ward HJT, Cousens SN, Smith-Bathgate B, et al. Obstacles to conducting epidemiological research in the UK general population. BMJ 2004;329:277-9.

22. Galea S, Tracy M. Participation rates in epidemiologic studies. Ann Epidemiol 2007;17:643-53.

23. Macfarlane GJ, Beasley M, Jones EA, et al. The prevalence and management of low back pain across adulthood: results from a population-based cross-sectional study (the MUSICIAN study). Pain 2012;153:27-32. 